\title{
O COGNITIVISMO É UM HUMANISMO
}

\author{
Cognitivism is a Humanism
}

Gustavo Arja Castañon ${ }^{1}$

\section{Resumo}

O Cognitivismo defende uma imagem de ser humano plenamente compatível com a defendida pela tradição humanista ocidental e o movimento da Psicologia Humanista norte-americana. O humanismo postula um ser humano com qualidades únicas no universo conhecido, que possui, portanto, necessariamente, algo natural e universal que o caracteriza, ou seja, uma natureza humana. No caso da Psicologia Humanista, acrescentase a este princípio básico o da crença num ser humano livre e auto-orientado. Implícita ou explicitamente, o Cognitivismo defende que o ser humano é: consciente, ativo, movido por causas e razões, orientado a metas, um processador de informação, tem seus processos cognitivos governados por regras, possui um inconsciente cognitivo, constrói as regras que coordenam sua cognição, possui tendências inatas, reage a significados atribuídos, tem emoções que atuam por meio da cognição, é epistemicamente motivado e constituído de mente e corpo que interagem e se influenciam mutuamente. Com a revolução cognitiva e 0 surgimento de uma abordagem que defende tal modelo de objeto para a Psicologia e testa suas hipóteses sobre ele pelo método experimental, o ainda nascente movimento humanista foi progressivamente perdendo força e razão de ser. O espírito reducionista, determinista e desumanizante, que segundo os humanistas era disseminado na Psicologia pelo Behaviorismo e pela Psicanálise, encontrava então um opositor muito mais poderoso, o Cognitivismo, que se ocupou de grande parte dos temas de investigação reivindicados pela Psicologia Humanista.

Palavras-chave: Cognitivismo; Psicologia humanista; Antropologia filosófica; Humanismo.

1 Graduado em Psicologia pela UERJ e em Filosofia pela UFRJ. É Mestre em Psicologia Social pela UERJ e Doutor em Psicologia pela UFRJ. Atualmente ministra cursos nas graduações em Psicologia das universidades Estácio de Sá e Católica de Petrópolis, e cursa o Mestrado em Lógica e Metafísica da UFRJ. Endereço para contato: UCP - Faculdade de Psicologia - Rua Barão do Amazonas, 124, Centro-Petrópolis-RJ - CEP 25685-070. e-mail: gustavocastanon@hotmail.com. 


\section{Abstract}

Cognitivism defends a human being image fully compatible with the one of the humanist western tradition and of the movement of the North American Humanistic Psychology. The Humanism postulates a human being with unique qualities in the known universe, therefore necessarily possessing something natural and universal that characterizes it, in other words, a human nature. In the case of the Humanistic Psychology, it is increased to this basic principle of the faith on a free and self-oriented human being. Implicitly or explicitly, Cognitivism defends that the human being is: conscious, active, moved by causes and reasons, oriented to goals, a information processor, rule-governed in their cognitive processes, a owner of a cognitive un conscious, constructor of rules that coordinate its cognition, a owner of innate tendencies, a attributed meanings reactor, has emotions that act through cognition, epistemically motivated and constituted of mind and body that interact and are mutually influenced. With the cognitive revolution and the appearance of an approach that defends such object model for Psychology and tests their hypotheses on him through the experimental method, the still recent-born humanist movement went progressively losing his meaning and strength. The reductionist, determinist and dehumanizing spirit that, according to the humanists, was disseminated by Behaviorism and Psychoanalysis in Psychology, had found a much more powerful opponent, the Cognitivism, which was in charge of great part of the investigation themes demanded by Humanistic Psychology.

Keywords: Cognitivism; Humanistic psychology; Philosophical anthropology; Humanism.

O título deste artigo parafraseia o da famosa conferência de Jean-Paul Sartre (1973), "O Existencialismo é um humanismo", na qual este filósofo procura defender contra cristãos e marxistas tese de que o existencialismo deve ser classificado como um humanismo. Nesta obra, Sartre nos oferece sua influente definição de humanismo como a doutrina que atribui ao homem um lugar único e característico em relação aos outros seres do universo. Visto desta forma, Sartre pode justificar seu existencialismo ateu como humanista, uma vez que esta doutrina filosófica sustenta que o ser humano é o único ser no universo no qual a existência precederia a essência. Esta definição sartreana do sentido geral do termo humanismo também é aceita por Pedro Dalle Nogare (1983), em obra na qual tenta responder que denominador comum poderíamos encontrar entre tantas doutrinas opostas entre si que reivindicaram no século $\mathrm{XX}$ o título de humanismo.

Este artigo procura apresentar evidências de que o Cognitivismo, abordagem contemporânea da Psicologia Moderna, pode reivindicar o título de humanismo, tanto no sentido conferido por Sartre ao termo, quanto pelo sentido mais estrito dado a este pela Psicologia Humanista norteamericana. Contra esta pretensão, pesa sobre 0 Cognitivismo a acusação que demonstrarei equivocada de que ele seria somente uma forma determinista disfarçada de computacionalismo. Mais do que isso, oferecerei evidências que sustentem a tese de que por materializar muitas das maiores esperanças do movimento humanista, o Cognitivismo acabou por ser a maior causa de seu esvaziamento.

\section{O que o Humanismo ex ige da Psico- logia?}

Na psicologia moderna, o conceito de humanismo ganhou contornos mais precisos, estabelecidos pelo movimento que atribuiu a si este título. A Psicologia Humanista, surgida nos Estados Unidos do pós-guerra, surgiu como um levante contra a imagem de ser humano que estava sendo difundida pela psicologia por meio do Behaviorismo e da Psicanálise. Contra o Behaviorismo, pesava a acusação de difundir uma imagem de ser humano meramente reativo, semelhante à "uma coisa passiva perdida, sem responsabilidade por seu próprio comportamento" (DeCarvalho, 1990, p. 33). Assim, o Behaviorismo veria o homem como um conjunto de respostas a estímulos, ou seja, uma coleção de hábitos independentes. Frick (1973), por exemplo, era um dos que acusava o Behaviorismo de haver buscado criar uma visão limitada do homem como máquina. A oposição do Humanismo ao Behaviorismo pode ser sintetizada em quatro pontos. Primeiro, não concordam com a pesquisa com animais como acesso a uma compreensão adequada do ser humano. Como disse Bugental (1963), o ser humano não é um rato branco maior, assim uma Psicologia baseada em dados 
animais excluiria aquilo que deveria ser o objeto primeiro da Psicologia: os processos e experiências distintamente humanos. Segundo, os humanistas exigem que os temas de pesquisa da Psicologia não sejam escolhidos por sua adequação ao método experimental, e sim por sua importância para o ser humano e relevância para o conhecimento psicológico. Terceiro, opõem à concepção reativa e mecanicista behaviorista do ser humano uma concepção proativa da natureza humana: os humanistas argumentam que a motivação humana é intencional e automotivada. Por último, afirmam que ainda que fosse possível ao Behaviorismo realizar um catálogo completo dos comportamentos humanos possíveis, isto não ofereceria uma descrição adequada da natureza humana, pois o ser humano é um todo único e indivisível.

Já contra a Psicanálise pesavam as mesmas acusações de determinismo e reducionismo, somadas às de dogmatismo e patologização da condição humana. As idéias de Freud sobre o ser humano seriam pessimistas, fatalistas e excessivamente centradas no "lado negro" do ser humano. Como diz DeCarvalho (1990), os humanistas argumentavam que para Freud "nada além de destruição, incesto e assassinato poderia se seguir se uma natureza básica humana encontrasse expressão completa" (p. 34), para ele, segundo Freud a pessoa permaneceria para sempre fixada em emoções originadas de traumas da infância. O homem não seria nada além de um produto de poderosas pulsões de fundo biológico, que se manifestariam de acordo com a história do passado de cada um. Como dizia Maslow, a Psicanálise somente estudava indivíduos perturbados: neuróticos e psicóticos: "o estudo de espécimes aleijados, enfezados, imaturos e patológicos só pode produzir uma Psicologia mutilada e uma filosofia frustrada" (1963, p. 234). A Psicologia deveria, portanto, se voltar para o estudo das qualidades e características positivas do Homem, como a alegria, o altruísmo, a fruição estética, a satisfação ou o êxtase. Enfim, psicólogos deveriam estudar o homem sadio, não somente a psicopatologia.

Contra o Behaviorismo e a Psicanálise, a Psicologia Humanista defendia uma visão de ser humano baseada nos seguintes pressupostos, enunciados pelo histórico artigo de James Bugental (1963), "Humanistic Psychology: A New Breakthrough": a) uma pessoa é mais que a soma de suas partes, b) nós somos afetados por nossas re- lações com outras pessoas, c) o ser humano é consciente, d) o ser humano possui livre-arbítrio, e) o ser humano tem intencionalidade. Assim que publicado, este artigo foi adotado como declaração da primeira associação deste movimento, a American Association for Humanistic Psychology (AAHP), o que indica sua representatividade.

Abraham Maslow (1968), consensualmente considerado o fundador do movimento humanista, ofereceu outra definição muito esclarecedora do que seria a essência de uma psicologia humanista:

1 - Cada um de nós tem uma natureza interna essencial, biologicamente alicerçada, a qual é, em certa medida, "natural", intrínseca, dada e, num certo sentido limitado, invariável ou, pelo menos, invariante. 2 - A natureza interna de cada pessoa é, em parte, singularmente sua e, em parte, universal na espécie. 3 - É possível estudar cientificamente essa natureza interna e descobrir a sua constituição (não inventar, mas descobrir). (p. 27)

Assim, de acordo com esta definição, toda teoria que afirme que o ser humano não tem uma "natureza humana", biologicamente alicerçada, não pode ser considerada humanista, mas da mesma forma, qualquer teoria que afirme que esta natureza determina completamente o que é o ser humano, desconsiderando o caráter único e irrepetível de cada indivíduo, também não poderia ser caracterizada como tal. É importante chamar a atenção para o fato de que o segundo postulado de Maslow defende implicitamente que o ser humano não é um ser absolutamente condicionado pelos fatores biológicos, psicológicos e sociais que influenciam sua constituição. Já o primeiro, garante um domínio de investigação no qual em tese poderiam ser estabelecidas leis naturais. Mas como conciliar num corpo de teorias científicas os efeitos resultantes do segundo postulado sobre o comportamento com as leis implícitas no primeiro e terceiro? Como conciliar liberdade e criatividade com leis naturais?

Para os humanistas, a Psicologia contemporânea se desenvolve na esteira de um velho conflito filosófico, o conflito apontado por Gordon Allport (1975) entre as tradições lockeana e leibniziana no pensamento psicológico e por Joseph Rychlak (1975) para quem somente o termo 'leibniziana' é substituído pelo termo 'kantiana'. 
Como defende Allport, para a tradição lockeana, o Homem é considerado um ser passivo, um receptáculo de impressões sensoriais que irá constituir seu intelecto. Esta é a teoria da white paper de Locke, que faz seu o axioma aristotélico de que "nada há no intelecto que antes não tenha passado pelos sentidos". Assim o ser humano seria um ser passivo atuando e se constituindo de acordo com os estímulos recebidos, sendo por eles, portanto, governado.

Leibniz iria ironicamente, no combate aberto à imagem lockeana de ser humano, acrescentar a esta sentença as palavras "a não ser 0 próprio intelecto". Ou seja, no mínimo, antes daquilo que passou pelos sentidos, está na mente a própria capacidade de assimilar e relacionar 0 material que é fornecido por estes, capacidade essa que não pode ser dada por eles. Leibniz qualifica o ser humano como livre, ativo e orientado propositivamente. O ser humano é um foco de atividade do universo, e não um mero objeto sofrendo a influência pura e simples das leis físicas. Assim, o humanismo rompe com a tradição mecanicista e cerra fileiras com a tradição leibniziana da Psicologia (e de universo) considerando o ser humano como consciente, auto-orientado e criativo, em suma, possuidor de livre-arbítrio.

Mais recentemente, o maior nome da Psicologia Humanista contemporânea, Joseph Rychlak (1988), em obra que pretende refundar a Psicologia Humanista, acrescentou aos pontos programáticos acima mais alguns, sendo o principal deles sua reivindicação de que no campo da teoria explicativa, as causas formais e finais devem ser readmitidas em seu pleno direito. Ou seja, para Rychlak, o conceito de agency, ou do sujeito proativo e orientado a metas, é central e sem ele nenhuma Psicologia digna do nome pode ser construída. Assim, como afirma Rychlak (1975) em seu clássico artigo "Psychological Science As a Humanist Views It", o humanismo é uma descrição teórica do comportamento em termos de causas formais e causas finais, mais do que em termos de causas materiais e causas eficientes, como no Behaviorismo e na Psicologia Fisiológica.

Portanto, para sustentar a tese deste artigo de que o Cognitivismo é uma abordagem que contempla as principais reivindicações da Psicologia Humanista, terão que ser oferecidas evidências de que ele considera que o ser humano: a) tem propriedades únicas no universo; b) possui uma natureza humana biologicamente alicerçada; c) possui um montante de liberdade; d) é consciente; e) é orientado a metas; f) não pode ter seu estudo meramente substituído pelo estudo de animais e, finalmente; g) precisa gerar uma Psicologia científica que investigue suas qualidades únicas e positivas. Para oferecer essas evidências, será apresentado um curto inventário de como o Cognitivismo define o ser humano.

\section{A imagem cognitivista de ser humano}

Ampliando a definição oferecida por Antônio Gomes Penna (1984), dividirei esta exposição em treze tópicos que caracterizam o modelo antropológico adotado pelo Cognitivismo (Castañon, 2006), conforme posições defendidas por seus autores mais significativos, como George Miller, Jerome Bruner, Roger Sperry, Noam Chomsky, Jean Piaget, Jerry Fodor, Urlic Neisser e Aaron Beck.

a) O ser humano é dotado de consciência - contra o Behaviorismo, o resgate do conceito de consciência como um fenômeno real, condicionado, mas não redutível ao biológico (Miller, 1985; Bruner, 1997; Sperry, 1993) é uma das características centrais da imagem de homem promovida pelo Cognitivismo. Cabe aqui acrescentar, no entanto, que por consciência não se entende um epifenômeno descartável, que uma vez excluído em nada alteraria as seqüências de comportamento a serem efetuadas por um organismo, conforme concebiam filósofos behavioristas e positivistas que ousavam abordar esta questão. No Cognitivismo, a consciência não é o fantasma na máquina de Gilbert Ryle (1949), ela é a dona da máquina. Nomes como Neisser (1967) e Sperry (1993) consideram a consciência uma propriedade emergente da atividade cerebral, que, no entanto, possui propriedades que não se reduzem às propriedades desta atividade. Isso leva ao interacionismo característico da posição mente-corpo do Cognitivismo, que veremos à frente. De resto, cabe aqui por último lembrar o argumento de Penna (1984, p. 45) em favor da relevância da consciência como fenômeno biológico, em contra dos pouco verossímeis argumentos de Ryle e dos behavioristas. Neste, lembra ele que a tese behaviorista da irrelevância da consciência não se compatibiliza com o fato de sua preservação ao longo do processo evolutivo, já que segundo a teoria da evolução a vida tende a des- 
cartar as formações emergentes inúteis e desnecessárias. Se a consciência fosse um simples epifenômeno, seu destino já teria sido o desaparecimento. Nesse ponto, é preciso escolher: ou o Behaviorismo ou o Evolucionismo.

b) O ser humano é ativo - a proatividade, o agency (poderíamos dizer, um certo montante de livre-arbítrio), é característica distintiva da imagem de homem oferecida pelo Cognitivismo. O ser humano não é uma bola de bilhar reativa num universo mesa-de-bilhar newtoniano-mecanicista. Ele é um foco de atividade do universo. Busca ativamente metas, constrói ativamente suas estruturas cognitivas, atribui ativamente significado. É o papel ativo e construtivo da consciência que impede que o Cognitivismo seja interpretado como uma teoria mediacional como a IA forte. Portanto, sem dúvida, podemos alinhar o Cognitivismo do lado da tradição leibniziana da Psicologia ou ainda kantiana contra a tradição lockeana. Piaget (1973) é representante paradigmático desta posição, com sua Psicologia do desenvolvimento calcada nos conceitos de organismo ativo e atividade do sujeito sobre o mundo construindo suas estruturas cognitivas. Para Piaget, o sujeito psicológico é um objeto que difere fundamentalmente dos corpos e das forças cegas que constituem os objetos das ciências físicas.

c) O ser humano é movido por causas e razões - o cognitivismo reconhece duas ordens de causalidade para o comportamento humano: as causas eficientes e as causas finais. A primeira se dá em virtude da natureza físico-química constitutiva do ser humano que é movida por leis estritas de causalidade, governada pelo mundo natural. A segunda se daria em virtude das propriedades emergentes da organização e atividade cerebral, a consciência e a atividade dela resultante, (Sperry, 1993). Penna (1984) expõe como este tipo de compromisso representa mais um afastamento radical da tradição positivista, uma vez que explicações centradas em razões são derivadas do conceito de escolha, e este, é indissociável do conceito de liberdade, que por usa vez é inconciliável com o determinismo laplaceano que caracteriza a visão de mundo positivista. No entanto, o Cognitivismo só considera que podemos estudar cientificamente causas finais quando estas já se encontram definidas em termos de causas formas, na forma de hierarquia de metas. $\mathrm{Ou}$ seja, podemos estudar a razão x como causa do comportamento y, mas nunca investigar as "causas" da razão x. Assim, o formato das leis sobre metas seria "quando o sujeito a possui a meta $\mathrm{x}$, nas condições y, o comportamento será w", e nunca poderia versar sobre como necessariamente chegamos a possuir a meta $\mathrm{x}$.

d) O ser humano é orientado a metas - $\mathrm{O}$ caráter agente do ser humano pode ser representado cognitivamente pelo conceito de metas, e dessa maneira abordado conceitualmente por meio da linguagem da cibernética e do conceito de feedback. É idéia central do Cognitivismo que o comportamento humano não pode ser adequadamente descrito, previsto ou compreendido em termos de estímulo-resposta e, portanto, pressões ambientais. Todo o comportamento humano é prospectivo e visa atingir metas por planos e estratégias de ação consciente. Como estabeleceram Miller, Galanter e Pribram (1960), podemos definir um plano de maneira rigorosa como um processo hierárquico de seqüências de operações a serem executadas por um organismo, da mesma forma como um programa para um computador. Se a isto acrescentarmos um modelo TOTE (test-operate-test-exit), estamos diante de um modelo cibernético de autoregulação orientada a metas, ou feedback. Num modelo de feedback negativo, que é o tipo que estamos avaliando, parte do output volta como input de forma a permitir a uma máquina cibernética (como um míssil) calcular a margem de erro entre a meta estabelecida (um alvo) e a atual posição da máquina (no caso posição no espaço), o que permite ao sistema ajustar seu comportamento (output) em relação à meta.

e) O ser humano é um processador de informação - é a metáfora computacional, a visão do ser humano como um organismo ativo que processa informação, primeiro a recebendo, depois a decodificando, a transformando, a armazenando, a recuperando e, por fim, a utilizando. É importante enfatizar novamente que o Cognitivismo (não as Ciências Cognitivas) sempre considerou a metáfora computacional somente uma metáfora, útil por oferecer linguagem e aparatos conceituais novos para a abordagem eficiente dos fenômenos cognitivos. O ser humano é mais do que um processador de informações (Neisser, 1967; Gardner, 1996; Sperry, 1993), porque tem uma consciência que atribui significados a estas informações e decide cursos de ações, mas é certo que ele também é um processador de informações, e o é, quase todo o tempo. 
f) O ser humano tem seus processos cognitivos governados por regras - este processamento não é aleatório, ele obedece a etapas processuais e a estruturas, ou seja, a regras estavelmente definidas. É certo que algumas destas regras podem mudar (o "programa", a estratégia), mas outras são muito básicas, são o "sistema operacional" de nossa mente, inatas ou ao menos inata é a tendência a desenvolvê-las. Os maiores expoentes desta posição no Cognitivismo, posição compartilhada em uma medida ou outra por todos os teóricos desta abordagem, são Chomsky (1971) e Fodor (1975).

g) $\mathrm{O}$ ser humano possui um inconsciente cognitivo - o ser humano processa informação e possui regras e estruturas para isso, que não é feito conscientemente a maior parte do tempo. Majoritariamente, o processamento de informação se dá de forma inconsciente, assim como são inconscientes a maior parte das regras e estruturas que governam este. Penna (1984) caracteriza o inconsciente cognitivo como um conjunto de estruturas e processos inacessíveis ou só muito dificilmente acessíveis à nossa consciência, e lembra que este conceito é derivado da filosofia de Leibniz. Chomsky \& Piaget estão entre os cognitivistas que abordaram explicitamente o problema, que hoje ganhou renovado interesse. Exemplos de processos e estruturas inconscientes são: a estrutura profunda da gramática transformacional de Chomsky, a linguagem do pensamento de Fodor, os estágios de desenvolvimento cognitivo de Piaget, as habilidades presentes na memória implícita e as atribuições perceptivas. A grande questão em aberto sobre o inconsciente cognitivo é em relação a sua acessibilidade ou inacessibilidade absoluta. No começo da revolução cognitiva a balança pendia para os que defendiam, como Chomsky (1981, 1987), a tese da inacessibilidade. Mas atualmente a tendência predominante é a de considerá-los ora subconscientes, ora regras e estruturas que podem ser representadas conscientemente. Aaron Beck, representante máximo da abordagem cognitivista da psicoterapia, é defensor da segunda tese. Ele declara sobre a relação entre os conceitos de pensamento automático e inconsciente cognitivo:

Os conceitos 'pensamentos automáticos' e 'inconsciente cognitivo' possuem muitos aspectos comuns. Embora a observação clínica te- nha revelado que os pensamentos automáticos são com freqüência muito facilmente admitidos à percepção consciente, a situação teórica da noção de 'automatismo' sugere que esse processamento cognitivo talvez seja melhor denominado de 'pré-consciente' (Beck \& Alford, 2000, p.27).

Portanto, existe atualmente a tendência no cognitivismo da divisão entre inconsciente cognitivo, que seriam as regras e estruturas não apercebidas de processamento, organização e armazenamento de informações, e subconsciente cognitivo, que seriam os processos automáticos de processamento de informação e atribuição de significado, não executados ou controlados pelo foco de atenção da consciência (como um sentimento desagradável por um lugar ou o comportamento de dirigir um carro).

h) O ser humano constrói as regras que coordenam sua cognição - no mínimo, o Cognitivismo acredita que a maior parte das regras, processos ou estruturas que coordenam o processamento de informação humano - a cognição - são construídas pelo sujeito em um processo de contínua interação com o mundo. Esta posição nós conhecemos hoje com o nome de construtivismo. Tem sua origem na Psicologia experimental com a obra revolucionária de Jean Piaget, que demonstrou como as formas de raciocínio humanas aparentemente mais naturais são na verdade construídas ao longo do desenvolvimento nas suas interações com o mundo. No entanto, o construtivismo característico da tradição cognitivista se faz acompanhar igualmente de uma tradição inatista, exigindo uma síntese superior entre estas duas posições que, no entanto, não parece mais problemática. Desde que Chomsky e Piaget promoveram o histórico encontro de Royaumont, em 1975 - envolvendo além deles nomes como Bärbel Inhelder, Hilary Putnam, Jerry Fodor, Gregory Baetson $\&$ Seymour Papert, entre outros (Piatelli-Palmarini, 1987) - vários esforços de síntese entre as duas posições anti-empiristas foram articuladas. Com o tempo, a boa e velha ciência moderna têm oferecido suas próprias soluções, demonstrando que algumas estruturas e habilidades muito básicas precisam ser consideradas inatas, evidentemente, sem a eliminação da necessidade de se postular processos de construção de estruturas (para um extenso inventário das evidências atuais em suporte do inatismo) (Pinker, 2004). 
i) O ser humano possui tendências inatas para desenvolver certas estruturas - conforme abordado, é igualmente representativa da tradição cognitivista a crença de que certas estruturas muito básicas da cognição, assim como certos processos também muito básicos, são inatos, ou no mínimo, que a tendência a desenvolvê-los é inata. Típico representante desta tradição é Chomsky (1971). As pesquisas contemporâneas em Psicologia do Desenvolvimento sobre as aptidões de recém-nascidos dão ampla sustentação ao inatismo, assim como a própria observação da natureza. A imensa maioria dos animais apresenta ao nascer grande repertório instintivo de comportamentos altamente complexos, adquiridos em longo processo de evolução de sua espécie. Não é surpresa constatar que o ser humano tenha no mínimo algumas estruturas e regras de processamento "pré-programadas", como um bios. Surpresa seria o contrário. No entanto, ambas as posições não são contraditórias. Primeiro, podemos considerar que existam estruturas e regras cuja potencialidade para se desenvolver é inata, mas cujo ato de seu desenvolvimento é construtivo. Também, poderíamos considerar que poucas e básicas regras e estruturas são inatas, a partir das quais muitas e complexas estruturas e regras são construídas.

j) O ser humano reage a significados atribuídos - como observou Penna (1984), esta tese do movimento cognitivista é herdada de George Mead. Este defendia que seres humanos não reagem a estímulos físicos, mas sim aos significados atribuídos a estes estímulos. Em última análise, poderia se encontrar a raiz deste pensamento na filosofia estóica. É famosa a máxima de Epicteto, segundo a qual o que comove o homem não são as coisas mesmas, mas sim suas opiniões sobre elas. Na Psicologia, entra pelas mãos de influente artigo de Sperry (1977). Diga-se de passagem, Bruner (1997) em suas últimas obras, reclama que o significado atribuído, e não o processamento de informação, deveria ser o verdadeiro objeto de estudo de uma Psicologia Cognitivista. Nos últimos anos, a questão do significado atribuído como 0 verdadeiro determinante do comportamento ganhou destaque renovado no Cognitivismo com a emergência da extremamente bem-sucedida Terapia Cognitiva, capitaneada por Aaron Beck e que faz dessa idéia uma pedra angular de sua teoria psicoterapêutica. k) O ser humano tem emoções que atuam por meio de cognições - o estudo cognitivo sistemático da motivação e emoção ainda é um capítulo em aberto do Cognitivismo e talvez o grande ponto fraco da abordagem, em virtude do não estabelecimento de um adequado sistema de referência para abordar a questão. A abordagem do processamento de informação tende a ser inadequada porque o sistema cognitivo, por uma conveniência metodológica, é considerado isoladamente das influências emocionais e motivacionais (Fodor, 1991). No entanto, o problema da motivação e emoção não deixou de receber contribuições originais desta abordagem, que inclusive tem se mostrado extremamente férteis no principal campo aplicado da Psicologia: a Psicoterapia. A posição canônica desta abordagem em relação ao problema das emoções é a de Jerry Fodor (1975), que transforma o conceito vago de desejo (ou os correlatos de vontade, impulso, instinto, pulsão, etc.) numa representação deste ("quero comida") que interagindo com representações de outras crenças (tem comida na geladeira) causa uma meta (apanhar comida na geladeira). A representação de uma meta, como toda representação, é computável e determina funcionalmente o comportamento do sistema. Caracteristicamente, as melhores contribuições neste campo vêm sendo dadas à imagem geral cognitivista de Ser Humano por dois campos da Psicologia que foram recentemente invadidos pela abordagem Cognitivista: A Psicologia Clínica e a Psicologia Social. No campo da Psicologia Clínica, a teoria cognitiva da personalidade (Beck \& Alford, 2000) postula que as emoções são mais conseqüências do que causas das cognições, logo, crenças disfuncionais geram emoções disfuncionais, mas o inverso também é verdadeiro. Ainda, não são os fatos (ou informações) que nos provocam emoções, mas nossas interpretações sobre eles. Da mesma forma, o Cognitivismo não vê nas motivações de origem fisiológica (fome, sede, sexo, sono) poder para determinar diretamente o comportamento dos sujeitos: como quaisquer outros estímulos, eles são informações sobre as quais atribuiremos significados, e é a estes que reagiremos, não aos estímulos. Esta não é uma idéia difícil de compreender: apesar da fome, o preso político continua sua greve de fome, pois ele vê nela uma arma política; apesar do desejo, o monge se comporta de maneira celibatária, pois interpreta o desejo sexual como uma tentação que o afastará do 
crescimento espiritual, não como um prazeroso processo biológico; já o libertino, come, bebe, dorme e faz sexo não porque não consiga controlar seus instintos, mas porque acredita que não consegue ou que não quer. Ambas as formulações partem do pressuposto de que a emoção e o desejo são subordinadas à razão.

l) O Ser Humano é também epistemicamente motivado - estas idéias sobre as relações entre motivação e cognição afirmam que parte de nossa motivação é meramente cognitiva, ou seja, voltada para a obtenção de conhecimento mais apurado do universo. E isso não se daria mediatamente, em virtude de um instinto de sobrevivência e, portanto, de vontade de poder, mas diretamente, como uma vontade de sentido. Apesar das inspirações fenomenológicas, gestaltistas e existencialistas desta idéia, pode-se dizer que ela vem desde o thaumátzein grego, ou seja, a tese de que o maravilhamento diante do real era a motivação básica da atividade filosófica. Como aponta Krüger (1986), foi a Psicologia Social Cognitiva que forneceu modelos testáveis destas teses, com a Teoria da Atribuição de Fritz Heider e a Teoria da Dissonância Cognitiva de Leon Festinger. Poderíamos dizer que estas teorias apresentam visões do Ser Humano sucessivamente como cientista ingênuo e como caçador de consistência. A visão do Ser Humano como caçador de consistência focaliza a questão de como as pessoas explicam seus comportamentos e os das outras pessoas, ou seja, quais as relações causais que elas atribuem ao mundo social, na tentativa de torná-lo prognosticável. Já segundo a teoria da dissonância cognitiva (Festinger, 1975), o Ser Humano se vê motivado quando percebe discrepâncias entre suas cognições. Quando ocorrem implicações contraditórias entre duas crenças importantes para uma pessoa, gera-se uma ansiedade que desemboca em pressões no sentido da redução dessa dissonância. Essa redução se daria necessariamente pelo abandono de uma das crenças, de ambas, ou pela introdução de uma nova. Assim, estes são dois exemplos de teorias cognitivistas (a primeira é de inspiração gestaltista) que ilustram a idéia básica do Cognitivismo de que a obtenção de conhecimento é ela própria uma motivação básica do ser humano. Tendo abordado estas doze características da imagem de homem oferecida pelo Cognitivismo, só nos resta abordar uma outra.

\section{A Psicologia Cognitiva e o Problema Mente-corpo}

É evidente que o cognitivismo promove uma distinção clara entre dois domínios de análise do ser humano, o físico e o mental. Foi Neisser (1967) o primeiro psicólogo cognitivo que assumiu plenamente as conseqüências da conquista filosófica de Hilary Putnam (1961) e percebeu a natureza da utilidade da metáfora computacional para a Psicologia Cognitiva. Muito embora ele já a considerasse inadequada "de muitos modos" (1967, p. 6), ele havia percebido que o grande serviço prestado por ela era demonstrar que, mesmo numa máquina lógica não-biológica como o computador, existem dois níveis de análise bem diversos: 0 do hardware e o do software. Isso legitimava a divisão entre um domínio de análise físico-cerebral e outro psicológico-mental no ser humano. $\mathrm{O}$ Psicólogo não está interessado em como os dados são registrados no $\mathrm{HD}$, e sim em entender como funcionam os programas, as cognições. É por isso que para Neisser a preocupação dos neurocientistas em como e onde a memória está armazenada é inútil para o psicólogo: "Ele quer entender sua utilização, não sua encarnação" (p. 6). Isso seria 0 mesmo para ele que querer que o Economista que procura entender o fluxo monetário de capitais na economia se dedique ao estudo de se as moedas físicas efetivamente utilizadas em certa transação foram de ouro, prata, cobre, ferro, papel ou ainda cheques. Essa posição de Neisser é fruto do decisivo ataque de Hilary Putnam (1961), desenvolvido anos depois por Jerry Fodor (1968), ao reducionismo do behaviorismo lingüístico e do materialismo eliminativo (e a tese da identidade estado mental - estado cerebral). Este ataque e os novos argumentos propositivos destes filóso fos fundaram uma corrente da Filosofia contemporânea decisiva para a Revolução Cognitiva: o Funcionalismo. A idéia central do Funcionalismo é que os estados mentais são estados funcionais de uma máquina ou de um cérebro, não estados cerebrais como queria a teoria da identidade, que como afirma Putnam, não passa de materialismo ingênuo e simplório. Estes estados funcionais são realizados por estados cerebrais, mas poderiam sê-lo por outro hardware (outro cérebro no caso) de maneira correlata ao que acontece quando você instala o mesmo programa em duas máquinas diferentes com 0 mesmo sistema operacional e o coloca para rodar. 
Pode-se estar falando de um 486 de um lado e um Pentium 4 do outro, mas se ambas as máquinas estão rodando num Windows 98 e ambos estão executando um programa Word 97 para abrir 0 mesmo arquivo, ambos os hardwares, que são diferentes, estão no mesmo estado funcional. Este é o conceito de Putnam (1961) de realizabilidade múltipla (de realizável). Conseqüentemente, a forma física de uma máquina ou de um cérebro é irrelevante para a determinação do papel funcional que ele realiza. O que Putnam propõe é que nossos estados mentais estão para os estados neurofisiológicos da mesma forma que os estados lógicos de uma máquina estão para os estados físicos dessa máquina. Assim, podemos reduzir esta idéia à célebre fórmula: A mente está para o cérebro como o software para o hardware. A idéia é de fato irresistivelmente simples, uma vez que conheçamos mesmo que superficialmente o funcionamento de um computador. Nós podemos com rigor determinar como funciona o Word for Windows, sem ter qualquer idéia de como isso está instalado e "rodando" em nosso hardware.

É necessário lembrar que o Cognitivismo aceita esta tese, mas não se limita a ela. Bruner (1997) lembra que, infelizmente, a metáfora computacional não significa a reabilitação científica dos estados intencionais da consciência e de suas qualidades subjetivas. Acreditar, desejar, compreender um significado passaram a ser as entidades que não deveriam ser aceitas na ciência cognitiva nascente. Isso no entanto vingou na Neurociência e na Inteligência Artificial, porém, como vemos, não no Cognitivismo.

Entendido isso, cabe inserir nossa pergunta: até que ponto é legítima a afirmação de que a posição da Psicologia Cognitiva para o problema mente-corpo representa um novo dualismo? Estamos aqui diante de um dualismo metodológico, mas será que isso equivale a um dualismo ontológico, a posição cartesiana de duas substâncias diversas e independentes, a res extensa e a res cogitans? Segundo a maioria dos Cognitivistas não. Eles continuam aderidos a um monismo geral, que considera só haver uma realidade natural, e que 0 universo é feito de uma única substância. Esta é a posição do próprio Neisser: "Da minha parte, eu não tenho dúvidas que o comportamento humano e a consciência dependem inteiramente da atividade do cérebro, em interação com outros sistemas físicos" (1967, p. 5). Porém, como vimos tam- bém de Neisser, o Cognitivismo não é reducionista: não há como reduzir o nível abstrato de análise das regras e estruturas cognitivas ao nível concreto da organização e atividade cerebral. Obviamente as operações lógicas de um programa podem ser descritas independentemente do hardware específico onde elas estão ou serão instaladas. Assim, "estados mentais" podem e devem ser descritos de forma completamente distinta dos "estados físicos" do cérebro.

No entanto, como lembram Eysenck \& Keane (1994), é também crença generalizada da Psicologia Cognitiva o princípio do isomorfismo entre mente e cérebro, ou seja, que ambos têm uma organização semelhante em suas estruturas. Isso faz com que a investigação do cérebro e de seu funcionamento normal e alterado (drogas, lesões) seja significativo para a investigação psicológica, pois a primeira produz pistas importantes para a segunda (no entanto o inverso tem sido muito mais verdadeiro nos últimos cinqüenta anos). Mas também é significativo que quando alguém postula que a atividade cerebral é semelhante à atividade mental, está assumindo paralelamente que ambas não são a mesma coisa. Portanto, todo isomorfismo é um dualismo, porém, não necessariamente ontológico.

Bernard Baars (1986) explicou bem o problema em que está envolvida a Psicologia Cognitiva. Por trezentos anos desde Descartes, o problema mente-corpo vem sendo discutido em termos da "substância fundamental da realidade": a realidade é material, mental ou dividida em ambas as substâncias? Depois do dualismo de substâncias cartesiano, duas outras posições básicas foram estabelecidas na Filosofia, ambas monistas: 0 monismo pan-psíquico e o monismo materialista. Para o primeiro, a única substância do universo é o Espírito, e tudo é mental. Para a segunda, a única substância do universo é a matéria, e só existe 0 mundo físico.

A Folk Psychology, o senso-comum, é dualista. Acredita-se em geral que possuímos duas espécies de realidade, a consciência ou a mente e o corpo ou o cérebro. Para o Behaviorismo Linguístico, não há dubiedade possível na atitude científica: a mente é uma ilusão, só o mundo físico é real. A consciência como iniciadora de ações, ou seja, como entidade que tem eficácia causal, é um incômodo fantasma na máquina que não tem explicação, portanto, não pode existir! Esta doutrina 
não considera, é claro, que tal posição é tão metafísica quanto a cartesiana ou a monadologia leibniziana, e como tal, não é em absoluto científica, além de ser inverossímil. Com a Psicologia Cognitiva, no entanto, o problema se agrava. Geralmente, como afirma Baars (1986), psicólogos cognitivos tendem a defender que a realidade é em última análise física (monismo materialista), e que a experiência subjetiva é simplesmente uma diferente perspectiva do mundo físico. O dualismo aqui poderia se dizer simplesmente metodológico, mas o que se demonstra é a completa independência entre dois diferentes níveis de análise, pois, como vimos, a informação não é, em nenhuma hipótese, algo físico. Isso faz desta primeira posição cognitivista acerca do problema mente-corpo uma posição muito frágil teoricamente e pouco sustentável metafisicamente.

Mas nem to dos os cognitivistas se sentem na obrigação de descartar de saída o dualismo cartesiano. Noam Chomsky (1971) defende explicitamente que a tese cartesiana do dualismo é perfeitamente racional e não pode ser descartada por princípio. Ele traça um interessante paralelo entre a tese cartesiana da substância mental e a tese newtoniana da gravidade. Lembra que os mesmos motivos que levavam os materialistas mecanicistas a atacar a teoria da gravidade os levavam a atacar a substância mental. Era inobservável diretamente, e muito pior, agia sobre os corpos de forma inobservável e à distância, algo inconcebível para os moldes da mecânica newtoniana. A força de ação à distância, a idéia de um princípio de atração como propriedade inata dos corpúsculos últimos da matéria, simplesmente não se encaixava no arcabouço geral da ciência, porém, ao contrário das teses cartesianas sobre a consciência, tinha esmagador poder preditivo, e, portanto, acabou sendo aceita.

Se o físico e o mental são heterogêneos, ou eles são independentes ou interdependentes. Isso tem que nos levar a um posicionamento de tipo paralelista ou interacionista. O gestaltismo defendia a primeira tese, conhecida como paralelismo psicofísico, que nunca alcançou posição de destaque na Neurociência e na Psicologia por possuir muitos pontos fracos e ser muito vaga, pouco explicativa e nada materialista (requisito de respeitabilidade científica para o Positivismo). Mas o Cognitivismo, passada a posição desarticulada inicial, evoluiu para a tese dualista envergonhada do interacionismo. O principal motivo para isso é que um funcionalismo do tipo advogado por Putnam (1961) (não por Fodor), apesar de ter demonstrado a irredutibilidade do mental ao físico, ainda não é um modelo adequado para as propriedades intencionais da consciência (Searle, 2000), sem o qual qualquer filosofia da mente é insuficiente. Entre as teorias interacionistas mais influentes, temos a elaborada pelo filósofo precursor do cognitivismo, Karl Popper, em conjunto com o neurologista John Eccles (1977). Afirma Popper (1975), em passagem esclarecedora de sua verdadeira posição:

Podemos conjecturar que a Consciência, por sua vez, é produzida por estados físicos; contudo, ela os controla em considerável extensão. Assim como um sistema legal ou social é produzido por nós e, todavia, nos controla, não sendo em qualquer sentido razoável 'idêntico' ou 'paralelo' a nós, mas interage conosco, assim também os estados de consciência (a 'mente') controlam o corpo e interagem com ele (p. 230).

O problema principal com o interacionismo tem sido a recusa em afirmar o que a mente é (Bunge, 1980), o que de fato é reconhecido pelo próprio Popper (1975, p. 230), que, no entanto, acredita que o interacionismo é uma resposta "quase trivial" ao problema de Descartes, e lida bem com nossa crença comum e aparentemente óbvia de que há um certo dar e tomar entre o corpo, que modifica a mente, e a mente, que modifica o corpo. Existe, defende Popper, retroalimentação, interação entre a atividade mental e outras funções do organismo. Esta outra passagem é perfeitamente esclarecedora de que, no entanto, seu dualismo não é (diga-se de passagem incoerentemente) um dualismo ontológico, e que portanto, é plenamente representativo do tipo de posição defendida pelo Cognitivismo: "como Descartes, proponho a adoção de um ponto de vista dualista, embora, sem dúvida, não recomende falar de dois tipos de substâncias interatuantes. Mas penso ser útil e legítimo distinguir dois tipos de estados (ou eventos) interatuantes, os físico-químicos e os mentais" (1975, p. 231).

Roger Sperry (1993), psicólogo neurocognitivo vencedor do prêmio Nobel, seguindo explicitamente a posição de Popper, procurou levar o interacionismo característico do Cognitivismo um 
passo à frente, procurando dizer o que a mente é, e por que poderíamos falar de dualismo sem falar de dualismo ontológico (ou de substâncias). Partindo do pressuposto holista de que "o todo é mais que a soma de suas partes", ou seja, de que os todos apresentam propriedades irredutíveis às propriedades das partes que o constituem, Sperry apresenta a consciência humana como uma propriedade emergente da atividade cerebral, que, portanto, adquire propriedades distintas daquela. Neste sistema interacionista, o caminho da causação entre o todo (a mente) e as suas partes constituintes (os neurônios) é bidirecional. No entanto ele é claro em afirmar que acredita que este "novo mentalismo" não é um novo tipo de dualismo ontológico.

É muito difícil concluir até que ponto teorias interacionistas como as de Popper \& Eccles e Sperry representam uma posição clara do Cognitivismo sobre o problema mente-corpo, como a behaviorista monista certamente era (embora inverossímil). John Searle (1992) é o filósofo da mente que com mais clareza restabeleceu o conceito de consciência na filosofia contemporânea. Em sua obra "The Rediscovery of Mind", ele elabora a agenda de questões a serem investigadas e resolvidas pela Ciência Cognitiva e Filosofia da Mente sobre o problema da consciência, oferecendo inclusive soluções para várias delas. Atualmente, a influência de sua obra começa a renovar algumas posições do Cognitivismo (Castañon, 2006b), mas ainda assim, diante de todas as dificuldades que vimos sobre a relação do Cognitivismo com o problema mente-corpo, podemos concluir que dois mil e quinhentos anos de Filosofia, cento e vinte cinco de Psicologia e cinqüenta de Ciência Cognitiva não fizeram muito pelo esclarecimento deste que é um dos maiores problemas da Filosofia e mistérios para todo ser humano.

\section{É portanto o Cognitivismo um Huma- nismo?}

Rychlak (1988) julga que não. Acredita ele que o grande mérito do Cognitivismo foi reintrodu-zir o campo das causas formais na explicação psicológica científica, mas que ele falhou como humanis-mo por não aceitar, da mesma forma como toda a Psicologia de matriz lockeana, as causas finais como legítimas fontes de explicação científi- ca. Uma vez que Rychlak (1988) identifica o Cognitivismo com a teoria mediacional que 0 antecedeu e com algumas teses da inteligência artificial, sua conclusão é que esta abordagem adere à mesma matriz conceitual lockeana do Behaviorismo. As teorias mediacionais falham em oferecer um genuíno resgate da causa final no domínio da explicação psicológica por três motivos. Primeiro, porque os mediadores (sinais, codificadores, regras, modelos) são inputs e, portanto, foram causados eficientemente no organismo; sendo assim (segundo), metas genuinamente produzidas pelo próprio organismo de forma independente da causação ambiental e genética não existem (a liberdade é um mito); então (terceiro), isto resulta num meio exclusivamente demonstrativo de descrever o curso dos comportamentos. Para Rychlak, portanto, o Cognitivismo é um Behaviorismo mediacional.

Rychlak (1988) acredita que o Cognitivismo afirma equivocadamente ter resolvido o problema do comportamento humano orientado a metas, ou seja, proativo, e com isso solucionada a questão teleológica em Psicologia. Voltamos aqui à famosa obra de Miller, Galanter e Pribram (1960), um dos marcos fundadores do Cognitivismo: "Plans and the Structure of Behavior". Para estes autores, podemos definir um plano de maneira rigorosa como um processo hierárquico de seqüências de operações a serem executadas por um organismo, da mesma forma como um programa para um computador. Este nós conhecemos hoje como TOTE (test-operate-test-exit), um modelo cibernético de auto-regulação orientada a metas, ou feedback. A diferença aqui para Rychlak é que temos um modelo formal para "dar conta" do fenômeno da intencionalidade do comportamento, não uma legítima aceitação da causa final. Temos causas formais e eficientes "dando conta" de uma formulação aceitável de parte dos aspectos proativos do comportamento. Para os autores cognitivistas citados, intenção é uma parte incompleta de um plano cuja execução já tenha começado. Rychlak questiona esta visão da atividade finalista humana, pois acredita que esta deveria dar conta não da hierarquia de um plano de ação, mas da própria definição dessa hierarquia e desse plano. Caso remetêssemos a questão a planos e hierarquias maiores, estaríamos sempre somente transferindo o problema da legítima causalidade final para trás, até termos que nos deparar com as metas e finalidades 
irredutíveis (por exemplo, o plano de ir à faculdade faz parte de uma meta mais elevada de terminar o doutorado, que faz parte de um plano mais extenso de formação profissional, que faz parte de uma meta mais básica de investigar profundamente certos problemas, que por sua vez precisa ser explicada sempre por uma hierarquia superior de metas).

Se um organismo está somente executando planos, então em qual sentido podemos falar de explicação teleológica? Só podemos falar de teleologia quando formulamos estes planos, comparamos planos diferentes e os escolhemos. A execução, assim como a execução de um programa, pode ser pensada em termos de feedback e causação eficiente, mas esta não é a questão para Rychlak (1988). Não teríamos aqui qualquer revolução em relação à imagem mecanicista de homem herdada do Behaviorismo. O comportamento continua a ser visto como explicado em termos de causa eficiente (impulsos neuronais) guiada pela causa formal do padrão do plano do "programa" (meta cognitiva). Mas onde está a verdadeira questão da proatividade, que é a escolha de planos e a decisão de executar o plano? Na imagem de homem do Cognitivismo como a vê Rychlak, em lugar nenhum.

Mas não é legítima a conceituação feita por Rychlak do Cognitivismo como uma mera teoria mediacional, para isso, teríamos que identificálo totalmente com somente uma de suas correntes, o computacionalismo, que advoga a tese da IA forte e está hoje praticamente extinto (Searle, 1992). Quando o Cognitivismo trata metas e propósitos como causas formais, em sua forma de crenças sobre a ordem hierárquica de ações a serem efetuadas para a consecução de uma meta, o faz não negando a ordem de causalidade final, mas negando que tal tipo de causalida de possa ser abordada de uma forma científica com conseqüências preditivas. De fato, é nisso que fracassa a Logical Learning Theory de Rychlak (1994). Se é verdade que raciocinamos dialeticamente e criativamente, também é verdade que neste campo nenhuma predição comportamental pode ser feita, e sem predição, não há ciência moderna. Assim, a obra de Rychlak não oferece solução para este problema, pois o aborda tentando agregar a causalidade finalista à explicação psicológica, submetendo hipóteses sobre esta a experimentos. O problema é que podemos colocar em teste estes planos uma vez construídos, mas não seu momento de criação e escolha. Assim, podemos investigar a causalidade final do comportamento humano somente depois que está constituída enquanto causa formal, enquanto meta e hierarquia de metas. Isto não significa a negação da existência de uma fonte legítima de causalidade final. Significa a constatação de que tal tipo de explicação não é compatível com a abordagem nomotética da ciência moderna. A explicação científica nomotética só suporta causas materiais, eficientes e formais, e isto por uma razão muito simples: só suposições a respeito destes tipos de causas são falsificáveis.

\section{Conclusão}

Como vimos, o Cognitivismo é compatível com os principais pré-requisitos programáticos estabelecidos pelo movimento humanista. Em primeiro lugar, garante ao ser humano lugar único entre os seres no universo, quando reserva ao ser humano capacidades cognitivas únicas entre os animais. Em segundo lugar, defende o conceito de natureza humana sustentando empiricamente 0 conceito de que todos os seres humanos possuem tendências inatas a desenvolver certas estruturas cognitivas, que seriam universais. Em terceiro, defende o conceito de proatividade, o agency, segundo o qual o ser humano constrói ativamente suas metas e estratégias, é capaz de desenvolver estruturas secundárias originais e atribui ativamente significado a todo e qualquer estímulo. Em outras palavras, mesmo condicionado por limitantes universais presentes em sua natureza, o ser humano é capaz muitas vezes de transcendê-las em função do pensamento criativo e da atribuição de significado.

Em quarto lugar, vimos que o conceito de consciência é central para o Cognitivismo, que rejeita a postura irrealista do Behaviorismo sobre esta e irracionalista da Psicanálise sobre ela. Para o cognitivismo, a consciência é o fenômeno mais básico e real da vida psicológica, propriedade emergente da atividade cerebral que passa em certa medida mesmo a comandá-la. Uma das funções centrais da consciência é o quinto ponto de concordância com o movimento humanista, a tese cognitivista de que o comportamento é orientado a metas, que são escolhidas e criadas ativamente pela consciência em interação com as demandas somáticas. Também encontramos concordância em 
relação à rejeição cognitivista ao estudo dos processos cognitivos por meio do comportamento animal. Para o Cognitivismo, a cognição humana tem propriedades únicas e qualitativamente (e não só quantitativa-mente) distintas em relação às propriedades cognitivas dos mamíferos superiores, e, portanto, só podemos testar hipóteses sobre ela mediante experimentos com sujeitos humanos.

Por fim, chegamos à principal utopia dos grandes nomes do movimento humanista, como Joseph Rychlak e Abraham Maslow: a constituição de uma legítima Psicologia (com o estudo de seres humanos e problemas humanos) científica (por meio do método experimental). É nesse ponto que o Cognitivismo alcançou seus maiores sucessos, e em meu julgamento, acabou por drenar toda a energia transformadora que a Psicologia apresentou na década de sessenta, quando nasciam juntos os dois movimentos. A Psicologia Humanista jamais conseguiu resolver seus dilemas metodológicos e epistemológicos, não conseguindo realizar a promessa de se tornar um programa estruturado a aplicar o método científico à investigação de problemas legitimamente humanos. Por sua vez, o Cognitivismo, que a princípio pareceu aos leigos e ao público externo dar sinais de adesão ao determinismo sofisticado, mas radical do computacionalismo, sobreviveu à derrocada deste nas ciências cognitivas e se constituiu na mais bemsucedida abordagem da Psicologia Moderna. Hoje, o cognitivismo e correntes integradas a este como a Psicologia Positiva e a Psicologia Evolucionista, em conjunto com as neurociências e por meio do método científico, se ocupam, além dos processos cognitivos básicos, de grande parte da temática exigida pelos humanistas para uma Psicologia legitimamente humana, como felicidade, humor, altruísmo, responsabilidade, o morrer, a criatividade, o sentimento estético, sonhos, empatia, metas, meditação e estados alterados da consciência. Por conta de tudo isso é perfeitamente legítimo afirmar que o Cognitivismo é um Humanismo.

\section{Referências}

Allport, G. (1975). Desenvolvimento da personalidade. São Paulo: Pedagógica Universitária.

Baars, B. J. (1986). The cognitive revolution in psychology. New York: Guilford.
Beck, A. \& Alford, B. (2000). O poder integrador da Terapia Cognitiva. Porto Alegre: Artmed.

Bruner, J. (1997). Atos de significação. Porto Alegre: Artes Médicas.

Bugental, J. (1963). Humanistic psychology: A new breakthrough. American Psychologist, 18, 563-567.

Bunge, M. (1980). Epistemologia. São Paulo: EDUSP.

Castañon, G. (2006). 0 cognitivismo e o desafio da psicologia científica. Tese de Doutorado, Instituto de Psicologia da Universidade Federal do Rio de Janeiro, Rio de Janeiro.

Castañon, G. (2006b). John Searle e o cognitivismo. Ciências \& Cognição, 3 (8) 96-109. Recuperado em 24 ago. 2006: www.cienciasecognicao.org.

Chomsky, N. (1971). Linguagem e pensamento. Petrópolis: Vozes.

Chomsky, N. (1981). Regras e representações. Rio de Janeiro: Zahar.

Chomsky, N. (1987). A propósito das estruturas cognitivas e do seu desenvolvimento: Uma resposta a Piaget. In: Piatelli-Palmarini, M. (Org.) Teorias da linguagem, teorias da aprendizagem (pp. 63-84). Lisboa: Edições 70.

DeCarvalho, R. (1990). A history of the third force in psychology. Journal of Humanistic Psychology, 30, p. 22-44.

Eysenck, M. \& Keane, M. (1994). Psicologia cognitiva: Um manual introdutório. Porto Alegre: Artmed.

Festinger, L. (1975). Teoria da dissonância cognitiva. Rio de Janeiro: Zahar.

Fodor, J. A. (1968). Psychological explanation: An introduction to the philosophy of psychology. New York: Random House.

Fodor, J. A. (1975). The language of thought. Cambridge, Massachusetts: Harvard University Press.

Fodor, J. A. (1991). Methodological solipsism considered as a research strategy in cognitive psychology. In: Boyd, R. \& Gasper, P. (Orgs.). 
The philosophy of science (pp. 651-669). Cambridge, Massachusetts: MIT Press.

Frick, W. (1973). Psicologia humanística. Buenos Aires: Guadalupe.

Gardner, H. (1996). A nova ciência da mente (Caon, C., trad.). São Paulo: Editora da Universidade de São Paulo.

Krüger, H. (1986). Introdução à psicologia social. São Paulo: Pedagógica e Universitária

Maslow, A. (1963). Motivacion y personalidad (Garí, J., trad.). Barcelona: Sagitário.

Maslow, A. (1968). Introdução à psicologia do ser (Álvaro Cabral, trad.). Rio de Janeiro: Eldorado.

Miller, G., Galanter, E. \& Pribram, K. (1960). Plans and the structure of behavior. New York: Holt, Rinehart \& Winston.

Miller, G. (1985). The constitutive problem of psychology. In: Koch, S. \& Leary, D. (orgs). A century of psychology as science (pp. 4046). New York: McGraw-Hill.

Neisser, U. (1967). Cognitive psychology. New York: Appleton-Century-Crofts.

Nogare, P.D. (1983). Humanismos e anti-humanismos. Petrópolis: Vozes.

Penna, A. G. (1984). Introdução à psicologia cognitiva. São Paulo: Pedagógica e Universitária.

Piaget, J. (1973). Psicologia e epistemologia: por uma teoria do conhecimento. Rio de Janeiro: Forense.

Piatelli-Palmarini, M. (Org.) (1987). Teorias da linguagem, teorias da aprendizagem. Lisboa: Edições 70.

Pinker, S. (2004). Tábula Rasa: A negação contemporânea da natureza humana. São Paulo: Companhia das Letras.
Popper, K. (1975). Conhecimento objetivo. São Paulo: Editora da Universidade de São Paulo.

Popper, K. \& Eccles, J. (1977). O Eu e seu cérebro. Brasília: Editora da UnB.

Putnam, H. (1961). Minds and machines. In: S. Hook (org). Dimensions of mind (pp. 221-231). New York: Collier.

Rychlak, J. (1975). Psychological science as a humanist views it. Nebraska Symposium on Motivation, 23, 205-279.

Rychlak, J. (1988). The psychology of rigorous humanism. New York: New York University Press.

Rychlak, J. (1994). Logical learning theory: A human teleology and its empirical support. Nebraska: University of Nebraska Press.

Ryle, G. (1949). The concept of mind. London: Hutchinson.

Sartre, Jean-Paul. (1973). O Existencialismo é um humanismo. (Coleção Os Pensadores, Vol. 45). São Paulo: Abril Cultural.

Searle, J. (1992). The rediscovery of the mind. Cambridge, Massachusetts: The MT Press.

Searle, J. (2000). Mente, linguagem e sociedade: Filosofia no mundo real (Rangel, F., trad.). Rio de Janeiro: Rocco.

Sperry, R. (1977). Bridging science and values: A unifying view of mind and brain. American Psychologist, 32 (4) 237-245.

Sperry, R. (1993). The impact and promise of the cognitive revolution. American Psychologist, 48(8) 878-885.

Recebido em/received in: 05/09/2006 Aprovado em/approved in: 14/10/2006 